\title{
Fraud Avoidance Using QR Codes on Transaction Process on Finding - Tutor Application in Android System
}

\author{
I Nyoman Pande Wahyu Dharmawan dan R.V. Hari Ginardi \\ Departemen Informatika, Fakultas Teknilogi Informasi, Institut Teknologi Sepuluh Nopember (ITS) \\ e-mail: hari@if.its.ac.id
}

\begin{abstract}
Finding-Tutor application is an app with Android basis. This application helps people in finding some tutors that are needed for students. In addition, Finding - Tutor also helps tutor service providers in marketing their services. This application helps the student to create a transaction order according with the students' criteria. The tutor provider can also choose transaction according to the ability he / she can teach. However, this application should be able to handle a fraud that occurs in a condition where the tutor provider services does not come to the location of the transaction. This condition happens because if there is no feature detecting that the student and tutor service provider has met, the tutor service provider can make a false data. This kind of false data is a tutor service provider give a data to system that the tutor service provider has been in the transaction location where the real condition is different. For that occasion, Finding Tutor application require a feature to handle this fraud. To do so, Finding - Tutor uses QR Codes scanner to handle this fraud. This feature works when the transaction is taken by the tutor service provider. Then the transaction data will automatically be generated into $Q R$ Codes. After that, the student must scan the QR Codes from tutor service provider to start the transaction. The test results of this feature indicate that the feature is running well. This feature can automatically convert over transaction data into $Q R$ Codes and can scan the QR Codes itself. Nevertheless, further development is still needed to keep pace with the development of technology, as well as the changing needs of users of this application.
\end{abstract}

Keywords-Android, Fraud, Mobile, QR Codes, Startup.

\section{INTRODUCTION}

$I^{2}$ NFORMATION Technology takes an important role nowadays which is embrace all parts of human life. For instance, Information Technology provides people needs in area of service provision. There are a lot of startup business emerged that provides a service and involves mobile technologies. However, a lot of business that is relying on these mobile technologies still not yet accommodate fraud handling which appears because of its system such as Finding - Tutor application. One of the example is fraud will happen in case of both tutor provider and consumer deceive the system and tell that they are already met each other. By that condition, system will give the permission to start the transaction. But, in reality, both tutor provider and consumer actually doesn't meet each other. As a result, consumer can give dummy rating in order to improve tutor provider's score. To avoid that condition, a new feature is necessary which will handle this fraud. In this paper, new feature with involving QR Code technologies is used to verify the transaction and avoid the fraud as well.

Meanwhile, QR code's usage has become popular on this era. This technology helps users to store data that is needed into 2 Dimension Image. This finding tutor verification feature is divided into two stages. On the first stage, system creates a
QR Codes based on transaction that is chosen by tutor provider. QR Codes will be used by tutor provider to start the transaction. On the next stage, consumers have to scan the QR Codes from tutor provider to indicate that both tutor provider and consumer have met each other on the real time. Transaction will be started right after consumers successfully scan the QR Codes which belongs to tutor provider.

\section{STUDY LITERATURE}

In the introduction, the paper has already explained about new feature using QR Codes to prevent consumer and tutor provider in deceiving system.

\section{A. $Q R$ Codes}

QR Codes is an abbreviation of Quick Response Codes. QR Codes is a 2 Dimension Image which has ability to store data in it. QR Codes itself, is an evolution of Barcode. Main difference between QR Codes and Barcode lied on the capacity of the stored data. QR Codes is built by Denso Corporation, a japan company focusing on automotive. QR Codes was published in 1994 with purpose of tracking vehicle on the manufacture to get fast respond as well as fast processing. [1]. Figure 1 shows the example of QR Codes.

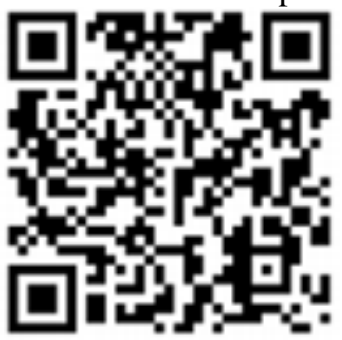

Figure 1. Example of QR Code

QR Codes itself has different structure with Barcode. According to ISO/IEC 18004, QR Codes is defined as a symbol which has structure containing data, version information, and error checking code [2]. A QR Codes has the shape of:

1. Quiet Zone, a circled QR Codes symbol represented by green color [2].

2. 3 Finder Patterns (FIP), which is located in the end of QR Codes represented by green color [2].

3. 2 Timing Patterns (TP), that is located between FIP and represented by blue color [2].

4. N Alignment Patterns (AP), is located inside the data area [2]. 
Figure 2 shows the structure of QR Codes.

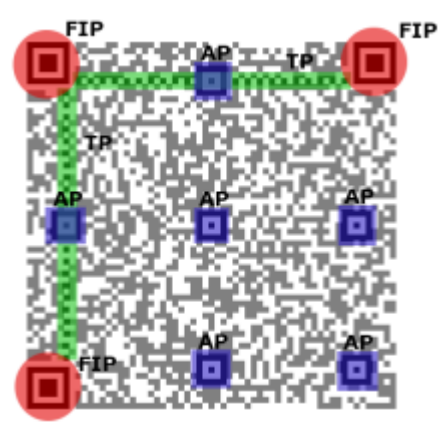

Figure 2. QR Codes Structure [2]

\section{1) QR Codes Reader}

QR Codes Reader is needed in order to read the data stored in QR Codes. There are a lot of applications belong to QR Codes Reader that should be installed first in mobile device to use it properly. Applications such as Kaywa Reader, Dakode, and ZXING provide QR Codes Reader feature. On those applications, they have a function to convert a QR Codes into a text so users can read it easily. Generally, reading processes are started by recognizing a white or black module located at the end side of QR Codes. After that, system will ensure the version that is used by QR Codes itself. Next, system will call error detection function which are contained in the QR Codes. Finally, system will return the value as a result of reading process of QR Codes. Figure 3 shows the flowchart of reading QR Codes.

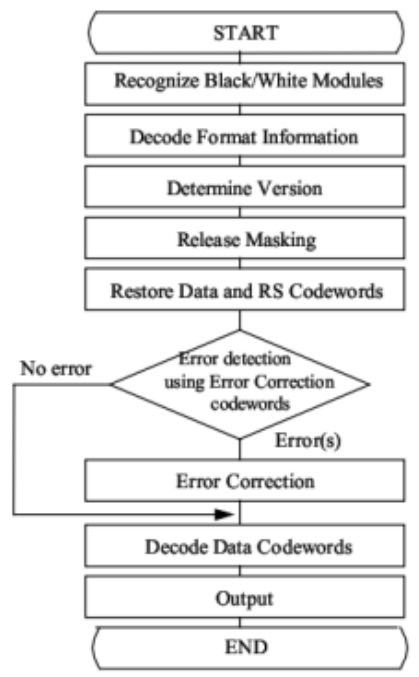

Figure 3. Flowchart of reading QR Codes [1]

\section{2) $Q R$ Codes Generator}

In order to change the specify data into a QR Codes, a software to generate text and number into QR Codes is needed. Some of applications such as Kaywa $Q R$ Codes, SnapMaxe and $Q R$ Codes Generator provides a feature to generate data into QR Codes. In general, the processes to make a QR Codes are the opposite with the processes to read a QR Codes. Firstly, the processes begin with analyzing and preparing data which will be generated into a QR Codes. Then, the system will run the error checking on the data. After that, the data will be changed into matrices and wrapped becoming a QR Codes. Later on, system will create form and give version information to the $\mathrm{QR}$ Codes. According to both error correction and masking function which is run parallelly with creating QR Codes, each word in the QR Codes represents different definition. Figure 4 shows the flowchart of generating QR Codes.

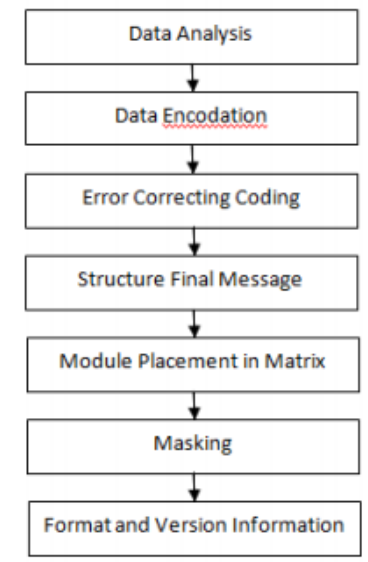

Figure 4. Flowchart of creating QR Codes [1]

\section{B. Volley Library}

Volley is a library used to manage networks. Volley is built by Google Company and published in the era of Google I/O in 2013. Volley is used in order to get over loss in Android SDK, whose needed as a network class that is able to work quietly without disturbing users [3]. The advantage provided by Volley Library is Volley library can operate network operation that use RPC model beautifully. Moreover, Volley Library also can run RPC's background very well [4].

\section{SYSTEM PLANNING}

On this chapter, this paper will explain application description in general, and feature in the application which will be used as a fraud avoidance. The feature itself will be divided into two sub chapters. Sub chapter one explains about how to generate specify data into QR Codes and sub chapter two explains in reading a $\mathrm{QR}$ Codes.

\section{A. Application Description in General}

Finding - Tutor application is an android app which is made to help consumer in order to find tutor provider. Consumer by using Finding - Tutor app can choose tutor provider that is fit with their criteria as well as choose the study topic. In addition, Finding - Tutor app can measure the level of urgency from the transaction made from the consumer.

Yet, on the Finding - Tutor app, there is still a fraud which can happen in the transaction section. Tutor provider can deceive the system creating a condition that both tutor provider and consumer has already met and transaction has already begun. So, consumer will get the disadvantage from the fraud that the reality tells differently. To avoid the condition, this paper uses fraud avoidance features implementing QR Codes technologies. First, after tutor provider choose the transaction, system will generate data from the transaction that is chosen into a QR Codes. The QR Codes will be used by tutor providers in order to tell the system that both tutor providers and consumers have met. Then, consumer should scan the QR Codes to send a value into a system so the system will be able to recognize that tutor providers and consumer have already met. Scan feature also has the meaning to avoid the difference of transaction duration between the input from consumer and the reality. After system is able to recognize the $\mathrm{QR}$ Codes, duration transaction countdown will be shown automatically on the consumer screen. When the transaction is over, consumer should scan again the QR Codes to tell the system that transaction time is 
already finished. If consumer doesn't scan once more time, tutor provider cannot take another transaction because the system read that the transaction is still running. The QR Codes itself actually has an hour active period until consumer scan the QR Codes for the first time. If the QR Codes doesn't get scanned during the active period, system will erase the QR Codes automatically and transaction between tutor provider and consumers are failed.

\section{B. Generating $Q R$ Codes}

On this chapter, in order to avoid the fraud which has been told in the previous chapter, tutor provider firstly should have QR Codes containing transaction id and tutor provider username. Later on, QR Codes is the key for starting the transaction. Figure 5 shows the flowchart of Finding - Tutor Application in generating QR Codes. In Figure 5, firstly, tutor provider has to take transaction from transaction lists. Then, system automatically changes the data containing transaction id and tutor provider username.

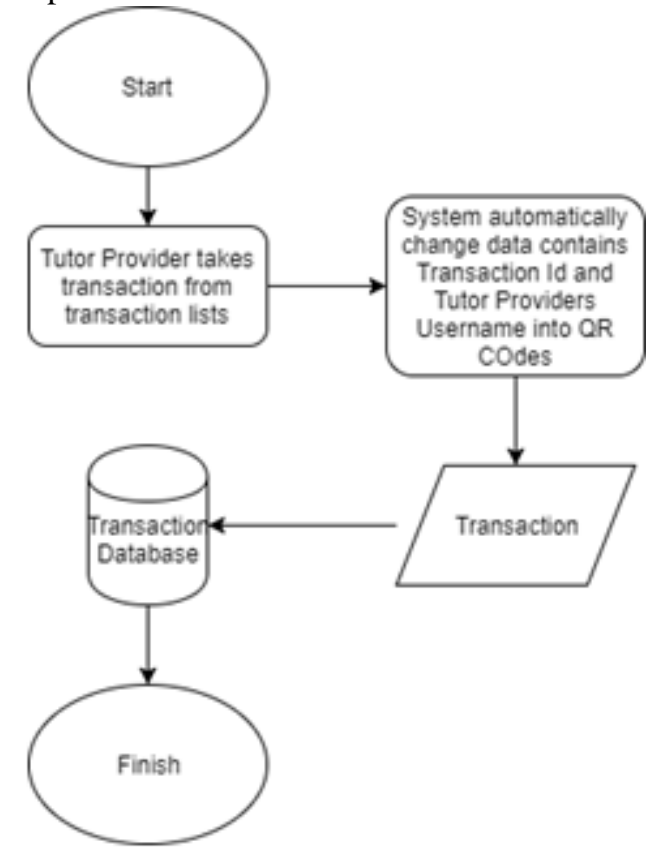

Figure 5. The Flowchart of Finding - Tutor Application in Generating QR Codes

In figure 5 also, after system gives QR Codes to tutor providers, system will store the data into transaction database. Next in figure 6, it shows the example of QR Codes data format used by Finding - Tutor Application.

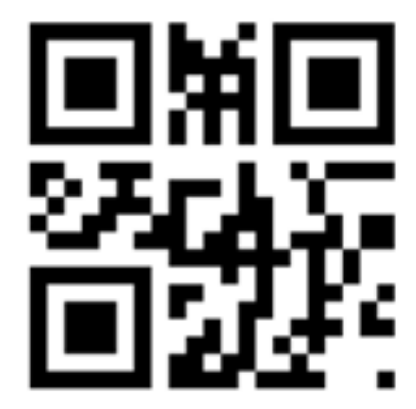

Figure 6. The Example of QR Codes Data Format

In Figure 6, The QR Codes itself contains data named 393nyoman. Word 393 means transaction id from the transaction table in database and word nyoman means tutor provider username. Between transaction id and tutor providers, there is a separation word symbolled ". ".

\section{Scanning QR Codes}

From the introduction, there are two chapters in order to avoid the fraud. On these chapter, consumers are involved to avoid the fraud using QR Codes scanner feature. In general, to avoid the fraud, the feature has to ensure that both tutor providers and consumers are met. To do so, consumers have to scan tutor provider QR Codes to tells the system that they are met each other. Figure 7 shows the flowchart of Finding Tutor application in Scanning QR Codes.

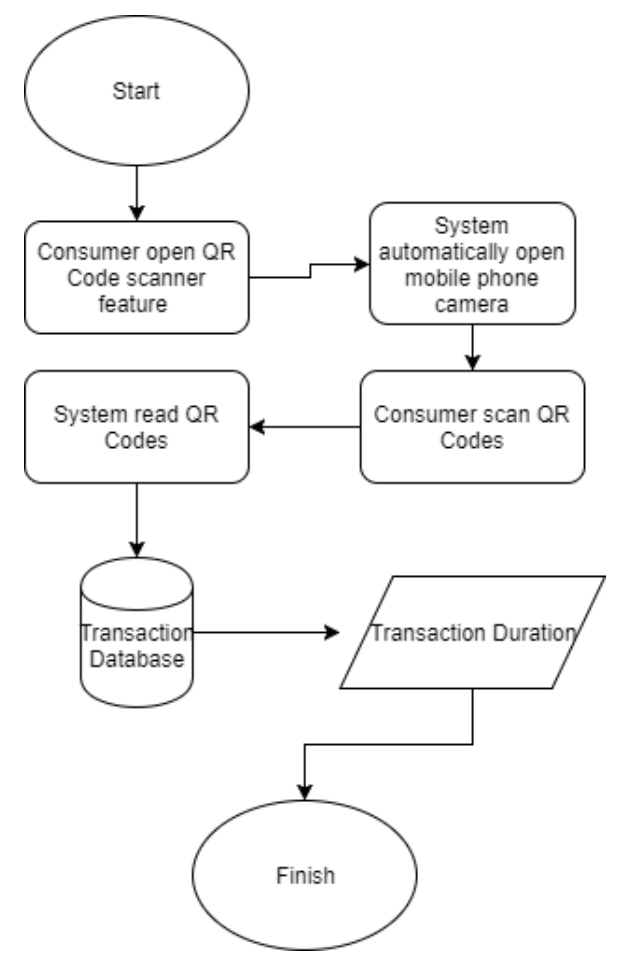

Figure 7. The Flowchart of Finding - Tutor Application in Scanning QR Codes

In figure 7, firstly, consumers have to open QR Code scanner feature to scan tutor providers QR Codes. After that, system automatically access mobile phone camera in order to scan the QR Codes. Next, Consumers should aim the QR Codes to read it. After system can read the QR Codes, system will take transaction duration from transaction table in the database. Finally, after system get the transaction duration, system will automatically show the duration countdown in the consumer mobile phone screen.

\section{IMPLEMENTATION}

The paper implementation shows both generating QR Codes feature and scanning QR Codes feature step by step. On this chapter also, interface views from each the feature are also shown. Table I show the environment in implementing and running the Finding - Tutor application in Android mobile apps.

Tabel 1.

Implementation Environment

\begin{tabular}{ccc}
\hline \hline Device & Type of Device & Specification \\
\hline \multirow{2}{*}{ Hardware } & Processor & Intel ${ }^{\circledR}$ Core $^{\mathrm{TM}} \mathrm{i} 5-\mathrm{CPU}$ \\
& Memory & $(2.60 \mathrm{GHz})$ \\
Software & Operation System & Windows 10 Pro
\end{tabular}

Table 1 shows that there are 2 type of device which is used in implementing the system. For Hardware, this paper used Intel Core i5 processor with 4GB memory. In addition, for software, this paper used windows 10 as an operation system and android studio as the IDE. For Android Studio, both PC or 
Laptop should have specification of memory 4 GB minimum in order to optimize IDE while compiling the code.

\section{A. Implementation of Generating $Q R$ Codes}

On the implementation, there are two feature that provides fraud avoidance, generating QR Codes feature and scanning QR Codes feature. In generating QR Codes as the paper told on the Chapter 3.2, firstly, tutor provider must select the transaction. After the transaction is selected, system automatically will generate data which contains transaction id, symbol “- ", and tutor provider username into a QR Codes. The QR Codes itself has an hour active periods. If QR Codes isn't being scanned during the active periods, system automatically will erase the QR Codes and set the transaction between consumers and tutor provider values into cancel. Figure 8 shows step by step the interface views in android mobile app shown in tutor providers screen app.
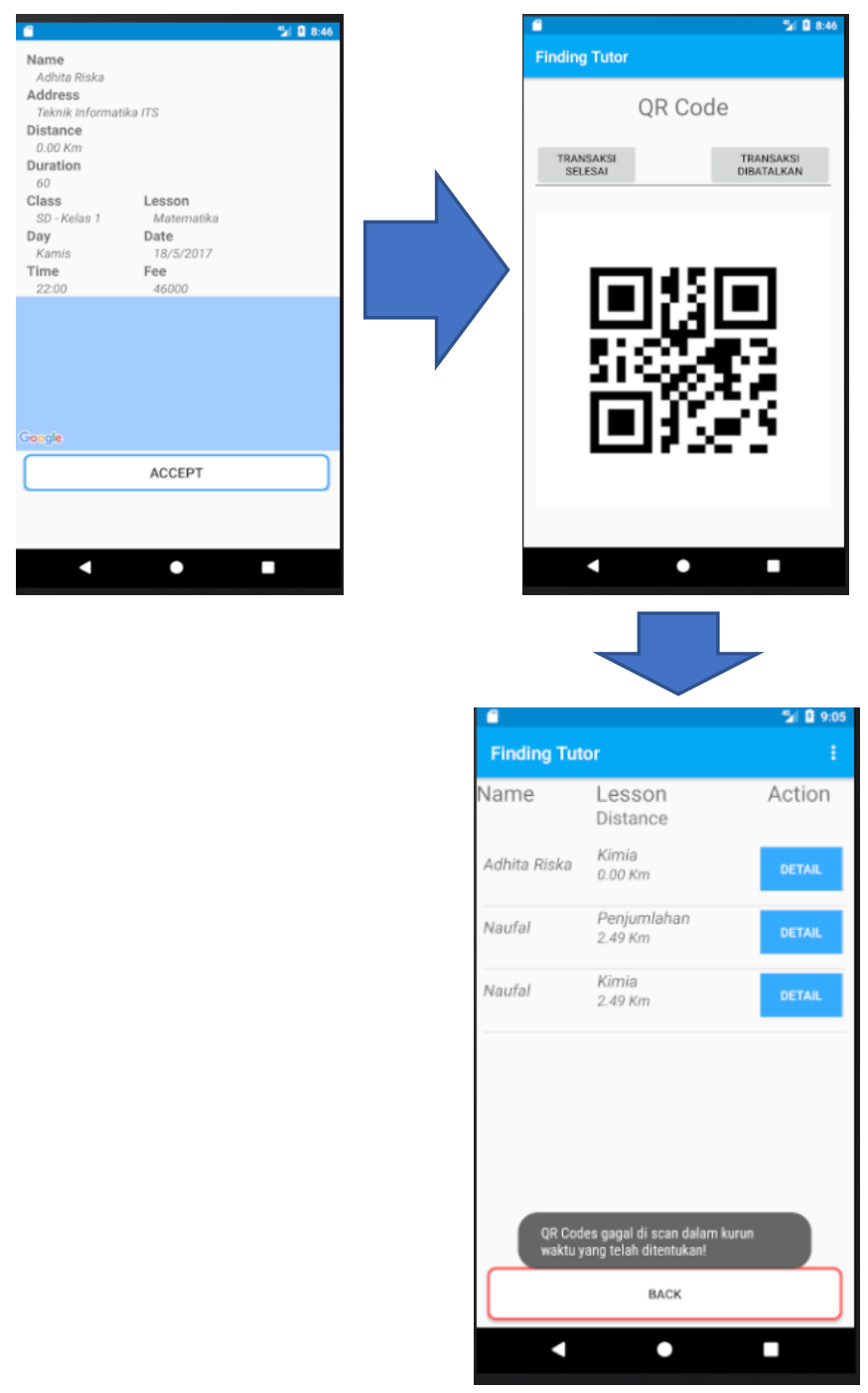

Figure 8. Interface View in Android Mobile Apps for Generating QR Codes

In Figure 8, there are three interface views for generating QR Codes. First interface view shows that tutor provider has already selected the transaction. After tutor provider push the accept button, system automatically generate data containing transaction id, symbol "-_ ", and tutor provider username into QR Codes, just like the second interface view shown. Lastly, on the third interface view, if QR Codes isn't being scanned during the active periods, system automatically will erase the QR Codes and set the transaction between consumers and tutor provider values into cancel. After that, system will give a notification to a tutor provider telling that transaction is cancelled.

\section{B. Implementation of Scanning $Q R$ Codes}

On this implementation, for the consumers, they should scan the QR Codes belongs to a tutor provider to indicate the system that transaction is ready to begin. The feature also helps consumer to meet the right tutor provider. There are three steps on scanning QR Codes feature. Consumers firstly have to open the scan feature. Then, system will automatically access consumers mobile phone camera in order to scan the QR Codes. After finishing the scanning, System will show the transaction duration countdown to show time remaining for the transaction. Figure 9 shows the interface view in Android mobile apps for scanning QR Codes.

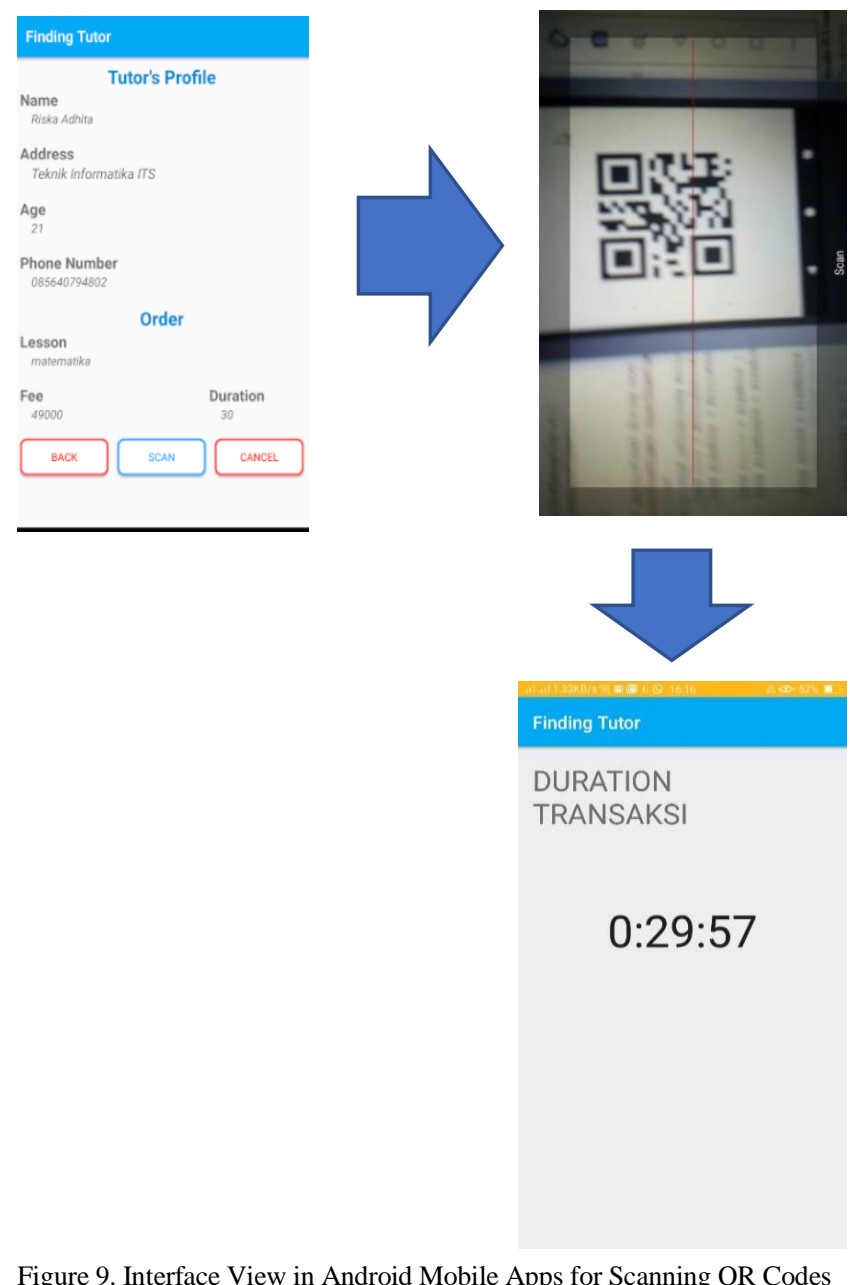

In Figure 9, there are three interface views for scanning QR Codes. First interface view shows that consumers get the tutor provider profile which takes consumers transaction. After consumers push the scan button, system automatically access mobile phone camera to scan tutor providers QR Codes. After finishing the scan, transaction duration countdown is shown in the consumers app.

\section{EXPERIMENT RESULT}

The paper experiment methodology designed to measure the effectiveness of the usage of scanning QR Codes. In order to do so, QR Codes which is already generated, will be scanned with some conditions. The purpose is to determine status of QR Codes, can it be scanned or not, and time execution of QR Codes. There are three conditions occur on this paper. First 
condition is QR Codes would be scanned by rotating QR Codes in the amount of 0 degree, 45 degrees, 90 degrees, and 180 degrees. For the second condition, QR Codes would be scanned with involving light. There are two types condition of lights which use bright light and obscure light. Last, for the third condition, QR Codes would be scanned by making QR Codes position into 0-degree slope and 30 degrees slope. This paper executed these three conditions five times with the distance between QR Codes and the camera for each condition are $10 \mathrm{~cm}$ and $20 \mathrm{~cm}$.

On the experiment, the paper should decide the environment of the experiment first. In order to get a good result, the paper uses the environment as table II shown.

Tabel 2.

Experiment Enviroment

\begin{tabular}{ccc}
\hline \hline Device & Type of Device & Specification \\
\hline Hardware & Android Type & Oppo Smartphone F1s \\
Memory & 4 GB 1600 \\
Operation System & Android Lolipop 5.1 \\
& IDE & Android Studio
\end{tabular}

On the Table II, the paper uses Oppo Smartphone F1s as its main mobile phone. Oppo mobile phone will be used to run the application where already made using Android Studio IDE. Oppo Smartphone has specification of 4GB memory and use Android Lolipop 5.1 Operation System.

In order to measure reliability of usage of QR Codes, experiments involving QR Codes scanner with some condition should be considered. On that occasion, this paper user three condition with involving QR Code rotation, Light adjustment, and slope location. Each condition is measured five times to get proper and exact result. Table III show the experiment result.

Tabel 3.

Experiment Result

\begin{tabular}{|c|c|}
\hline \multirow[t]{2}{*}{ Condition } & Result of Five Experiment \\
\hline & Time Execution \\
\hline
\end{tabular}

0 Degree rotation with $10 \mathrm{~cm}$ Succeed distance

45 Degree rotation with $10 \mathrm{~cm}$ Succeed distance

6.2525 Seconds

8.308 Seconds

90 Degree rotation with $10 \mathrm{~cm}$ Succeed distance

4.098 Seconds

180 Degree rotation with $10 \mathrm{~cm}$ Succeed distance

4.356 Seconds

0 Degree rotation with $20 \mathrm{~cm}$ Succeed distance

45 Degree rotation with $20 \mathrm{~cm}$ Succeed distance

90 Degree rotation with $20 \mathrm{~cm}$ Succeed distance

180 Degree rotation with $20 \mathrm{~cm}$ Succeed distance

Bright Light with $10 \mathrm{~cm}$ distance Succeed

\begin{tabular}{|c|c|c|}
\hline $\begin{array}{l}\text { Obscure Light with } 10 \quad \mathrm{~cm} \\
\text { distance }\end{array}$ & Succeed & 3.092 Seconds \\
\hline Bright Light with $20 \mathrm{~cm}$ distance & Succeed & 2 Seconds \\
\hline $\begin{array}{l}\text { Obscure } \\
\text { distance }\end{array}$ & Succeed & 2.318 Seconds \\
\hline $\begin{array}{l}0 \text { - degree slope with } 10 \mathrm{~cm} \\
\text { distance }\end{array}$ & Succeed & 3.354 Seconds \\
\hline $\begin{array}{l}30 \text { degrees slope with } 10 \mathrm{~cm} \\
\text { distance }\end{array}$ & Failed & 60 Seconds \\
\hline $\begin{array}{l}0-\text { degree slope with } 20 \mathrm{~cm} \\
\text { distance }\end{array}$ & Succeed & 1.314 Seconds \\
\hline $\begin{array}{l}30 \text { degrees slope with } 20 \mathrm{~cm} \\
\text { distance }\end{array}$ & Failed & 60 Seconds \\
\hline
\end{tabular}

On Table III, it can be concluded that QR Codes was able to be read in the most of experiment condition. In rotation condition, the results show, all of the requirement conditions such as 45-degree rotation or 90-degree rotation with $10 \mathrm{~cm}$ distance and $20 \mathrm{~cm}$ distance, succeed status with time execution gives less than 10 seconds. Other than that, on another condition, both bright light and obscure light, the results tell that QR Codes could be read on that condition with time execution consumes less than 5 seconds. On the other hand, move towards to third condition which involves 0 degree slope and 30 degrees slope, the results are various. For the condition involving 0 - degree slope, with both $10 \mathrm{~cm}$ and $20 \mathrm{~cm}$ distance, the results give the same result with previous conditions. They show succeed status and consume less than 5 seconds. On the contrary, for the condition involving 30 degrees slope with distance $10 \mathrm{~cm}$ and $20 \mathrm{~cm}$, both the results show failed status with time consuming is 60 seconds. It means that QR Codes cannot be read with minimum 30 degrees slope on any kind of distance.

\section{CONCLUSION}

The paper has introduced new application called FindingTutor application. Finding-Tutor application is an android apps that helps consumer in finding tutor provider. Yet, there is a fraud might happen on the system which involves both tutor provider and consumer. Tutor provider can deceive the system by giving fake status telling that tutor provider has met the consumer and transaction is already started. To avoid the fraud, this paper built a new feature with the usage of QR Codes technologies. Tutor provider will receive a QR Codes representing a transaction that has been chosen and Consumer has to scan the QR Codes in order to start the transaction.

From the experiment with creating three conditions, QR Code rotation, light adjustment, and slope location, both QR Code rotation and light adjustment give a succeed status in the distance of $10 \mathrm{~cm}$ and $20 \mathrm{~cm}$. It means that $0-$ degree, 45 degrees, 90 degrees, and 180 degrees rotation on scanning the QR Codes doesn't affect the system in reading data from QR Codes. The results show system only need not less than 10 seconds to read QR Codes. Similarly, light adjustment condition also shows succeed status and takes less than 5 seconds. On the other hand, slope location experiments give various results. If the slope is $0-$ degree, QR Codes still readable, but if the slope is 30 degrees, QR Codes starts to unreadable. 


\section{REFERENCES}

[1] D. I. R. M. M. . Pasca Nugraha, "Pengembangan QR Code Generator dan QR Code Reader dari Data Berbentuk Image," in Konferensi Nasional Informatika, 2011.

[2] S. P. Fattane Zarrinkalam, Mohsen Kahani, "Using Graph Database for File Recommendation in PAD Social Network," in 7th International Symposiun on Telecommunciations(IST'2014), 2014.

[3] N. S. T. H. Luiz F. F. Bellusi, "Fast QR Code Detection in Arbitrarily Acquired Images," in 24th SIBGRAPI Conference on Graphics, 2011, pp. 28-31.

[4] G. Segato, “An Introduction to Volley,” 2015. [Online]. Available: https://code.tutsplus.com/tutorials/an-introduction-to-volley--cms23800 . 